\title{
Effect of water contamination on the shear bond strength of five orthodontic adhesives
}

\author{
Ascensión Vicente ${ }^{1}$, Manuel Toledano ${ }^{2}$, Luis A. Bravo ${ }^{3}$, Alejandro Romeo ${ }^{4}$, Blanca de la Higuera ${ }^{5}$, Raquel \\ Osorio $^{6}$
}

${ }^{1}$ DDS, PhD. Contracted Doctor Professor. Orthodontic Teaching Unit, University of Murcia

${ }^{2} \mathrm{MD}, \mathrm{BDS}, \mathrm{PhD}$. Professor Department of Dental Materials ,University of Granada, Spain

${ }^{3}$ MD, DDS, MS, PhD. Professor Orthodontic Teaching Unit, University of Murcia, Murcia Spain

${ }^{4}$ LDS, PhD. Assistant Professor, Department of Orthodontics, University of Barcelona, Barcelona Spain

${ }^{5}$ PhD. Assistant Professor Department of Orthodontics, University of Barcelona, Barcelona Spain

${ }^{6} \mathrm{LDS}, \mathrm{PhD}$. Professor Department of Dental Materials, University of Granada, Spain

Correspondence:

Orthodontic Teaching Unit

University of Murcia

Hospital Morales Meseguer, $2^{a}$ planta

C/. Marqués de los Vélez, $s / n$

30008 Murcia, Spain

ascenvi@um.es

Received: $16 / 11 / 2009$

Accepted: 24/12/2009
Vicente A, Toledano M, Bravo LA, Romeo A, De la Higuera B, Osorio $\mathrm{R}$. Effect of water contamination on the shear bond strength of five orthodontic adhesives. Med Oral Patol Oral Cir Bucal. 2010 Sep 1;15 (5):e820-6.

http://www.medicinaoral.com/medoralfree01/v15i5/medoralv15i5p820.pdf

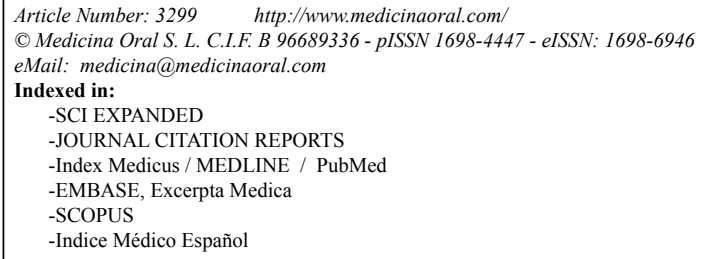

\begin{abstract}
Objectives: To evaluate the shear bond strength and site of failure of brackets bonded to dry and wet enamel. Study design: 50 teeth were divided into ten groups of 5 teeth each (10 surfaces). In half the groups enamel was kept dry before bonding, and in the other half distilled water was applied to wet the surface after etching. The following groups were established: 1)Acid/Transbond-XT (dry/wet) XT; 2) Transbond Plus Self Etching Primer (TSEP)/Transbond-XT paste (dry/wet); 3) Concise (dry), Transbond MIP/Concise (wet), 4) FujiOrtho-LC (dry/ wet); 5) SmartBond (dry/wet). Brackets were bonded to both buccal and lingual surfaces. Specimens were stored in distilled water $\left(24\right.$ hours at $\left.37^{\circ} \mathrm{C}\right)$ and thermocycled. Brackets were debonded using a Universal testing machine (cross-head speed $1 \mathrm{~mm} / \mathrm{min}$ ). Failure sites were classified using a stereomicroscope. Results: No significant differences in bond strength were detected between the adhesives under wet and dry conditions except for SmartBond, whose bond strength was significantly lower under dry conditions. For all the adhesives most bond failures were of mixed site location except for Smartbond, which failed at the adhesive-bracket interface. Conclusions: Under wet conditions the bonding capacity of the adhesives tested was similar than under dry conditions, with the exception of SmartBond which improved under wet conditions.
\end{abstract}

Key words: Moisture, resin-reinforced glass ionomer cement, moisture-insensitive primer, moisture-active primer, self-etching primer, brackets, bonding. 


\section{Introduction}

The presence of moisture is an inherent condition when bonding in the oral cavity and has long been considered as the most common reason for bond failure. Contamination causes plugging of the porosities produced by acid etching and a reduction in surface energy. In this way, resin penetration is impaired, and micromechanical retention is compromised (1). The detrimental effect of moisture on orthodontic bonding may also be due to water absorption and induction of the plasticizing effect in the polymer network. The latter involves the creation of hydrated zones at the polar monomer sites and the oxidation of pendant $\mathrm{C}=\mathrm{C}$ bonds attached to the network which release by-products such as formaldehyde so producing a plasticizing effect (2).

Bonding brackets with conventional composite resins involves a series of technique-sensitive steps and requires a completely dry field of operation throughout the bonding procedure.

In recent years, manufacturers have introduced adhesives that do perform in a moist environment. In particular, resin-modified glass ionomer cements (RMGIC) were developed to overcome the problems of the moisture sensitivity of composites and the low mechanical strength of glass ionomers, while maintaining the clinical advantages of conventional glass ionomers: a chemical bond to enamel, adhesion in a wet field (3) and fluoride release (4).

Moisture insensitive primers, which contain hydrophilic components such as hydroyethyl methacrylate (HEMA), and moisture-active adhesives based on cyanoacrylate have also been introduced to overcome the problem of bonding in a wet field.

Manufacturers claim that self-etching primers perform equally well in either a wet or dry environment. However, controversy over the results obtained with these products persists. Some studies have observed bond strength values similar to those achieved using the traditional acid-etch technique (5). Others have found that the bond strength of self-etching primers was lower (6) than when conventional procedures were followed. There are also studies that have found that self-etching primers provide higher bond strengths than the traditional system (7). These systems are applied without needing to be rinsed, unlike conventional etchants; after the application of the self-etching primer, the surface of the enamel must be air-dried because these products contain solvents such as water, ethanol and acetone (8). When self-etching primers are used, three mechanisms act to halt the etching process. First, the acid groups attached to the etching monomers are neutralized in a similar manner to the neutralizing of phosphoric acid by forming a complex with the calcium from the hydroxyapatite. Second, as the solvent is removed during the air-drying step, viscosity increases, slowing the transport of acid groups to the enamel interface. Finally, the primer is light-cured, the monomers polymerized and the transport of acid groups to the interface stopped.

There are several orthodontic studies concerning the performance of RMGIC, moisture insensitive primers, moisture-active primers and self-etching primers. Nevertheless, to our knowledge they have never been evaluated together in the same study under dry and wet conditions. The aim of this study was, therefore, to evaluate the shear bond strength and the site of bond failure of brackets bonded to enamel with a RMGIC ( Fuji Ortho LC, GC America Inc, Chicago, Ill), a moisture insensitive primer (Transbond MIP, 3M Unitek Dental Products, Monrovia, Calif), a moisture-active primer (SmartBond, Gestenco International, Goteborg, Sweden) and a self-etching primer (Transbond Plus self etching primer, TSEP, 3M Unitek) under both wet and dry conditions. The null hypothesis tested was that there are no significant differences in bond strength and debond site location among brackets bonded to enamel with these products under either wet or dry conditions.

\section{Materials and Methods}

A total of 50 human extracted premolars were stored in a 0.5 chloramine $\mathrm{T}$ solution at $40 \mathrm{C}$ for a maximum of six months following extraction. The buccal and lingual surfaces of each crown were cleaned with fluoride-free pumice in a rubber cup, sprayed with water, and dried with a compressed oil-free air stream for about 15 seconds. All teeth were divided at random into ten groups of 5 teeth each (10 surfaces). In half of the groups enamel was kept dry before bonding and in the other half distilled water was applied and enamel surfaces were kept moist after etching and before bonding. The chemical composition of each adhesive according to the manufacturer is shown in (Table 1). Bonding procedures and materials used were as follows: 1) Acid/Transbond-XT (dry/wet): After etching, a layer of Transbond-XT primer was applied to the tooth. Transbond XT paste was applied to the base of the bracket, which was then placed on the tooth pressing firmly. The adhesive was light-cured.

2) TSEP/Transbond-XT paste (dry/wet): The enamel was treated with TSEP, which was gently rubbed onto the enamel for 3 seconds. A moisture-free air source was used to deliver a gentle burst of air to the primer. The bracket was bonded with Transbond-XT paste as in group I.

3) Concise (3M Unitek) (dry). TMIP/Concise (wet): After etching, equal portions of resin $\mathrm{A}$ and $\mathrm{B}$ were mixed (for 5-10 seconds) and a layer of the resin was applied to the enamel. Then straight away, paste A and B were mixed vigorously (for 20 seconds) and the adhesive was applied to the bracket base, which was then placed on the tooth pressing firmly. After etching, the moist enamel surfaces were primed with Transbond MIP instead of Concise primer. A gentle burst of air was delivered to the primer (2-5 seconds) and then it was light-cured. 
4) Fuji Ortho LC (dry/wet): After etching, the cement was activated. The adhesive was applied to the bracket base, which was then placed on the tooth pressing firmly. Excess adhesive was removed from around the base of the bracket and the adhesive was light-cured.

5) SmartBond (dry/wet): After etching, a layer of the adhesive was applied to the bracket, and the bracket was placed on the tooth pressing firmly.
Etching procedure was carried out with $37 \%$ ortophosphoric acid (Vivadent Ets., Schaan, Lichtenstein) for 15 seconds, washing and drying for 30 seconds.

Altogether, one hundred stainless steel orthodontic brackets (Roth prescription minitaurus, nominal surface area $5.22 \mathrm{~mm}$ ) (R.M.O. Inc, Denver, CO, USA) were directly bonded.

Materials were always handled according to the manu-

Table 1. Composition of the adhesives according the manufacturer.

\begin{tabular}{|c|c|c|}
\hline Adhesive & Composition & $\%$ by Wt \\
\hline Fuji Ortho LC & $\begin{array}{l}\text { Liquid: } \\
\text { Polyacrylic acid } \\
\text { 2-Hydroxyethilmethacrylate } \\
\text { 2,2,4,Trimethyl hexamethylene dicarbonate } \\
\text { Triethyleneglycol dimethacrylate } \\
\text { Powder: } \\
\text { Alumino-silicate glass }\end{array}$ & $\begin{array}{c}20-22 \\
35-40 \\
5-7 \\
4-6 \\
100\end{array}$ \\
\hline Transbond XT & $\begin{array}{l}\text { Primer: } \\
\text { Triethylene glycol dimethacrylate } \\
\text { Bisphenol A Diglycidyl ether dimethacrylate } \\
\text { Paste: } \\
\text { Silane treated quartz } \\
\text { Bisphenol A Diglycidyl ether dimethacrylate } \\
\text { BisphenolA Bis(2-Hydroxyethil ether)dimethacrylate } \\
\text { Dichlorodimethylsilane reaction product with silica }\end{array}$ & $\begin{array}{c}45-55 \\
45-55 \\
70-80 \\
10-20 \\
5-10 \\
<2 \\
\end{array}$ \\
\hline Concise & $\begin{array}{l}\text { Primer A: } \\
\text { Triethylene glycol dimethacrylate } \\
\text { Bisphenol A Diglycidyl ether dimethacrylate } \\
\text { 2-Benzotriazolyl-4- Methylphenol } \\
\text { 2,2'-(P-Tolylimino)Diethanol } \\
\text { Primer B: } \\
\text { Triethylene glycol dimethacrylate } \\
\text { Bisphenol A Diglycidyl ether dimethacrylate } \\
\text { Benzoyl peroxide } \\
\text { Paste A: } \\
\text { Silane treated quartz } \\
\text { Bisphenol A Diglycidyl ether dimethacrylate } \\
\text { Triethylene glycol dimethacrylate } \\
\text { Dichlorodimethylsilane reaction product with silica } \\
\text { PasteB: } \\
\text { Silane treated quartz } \\
\text { Bisphenol A Diglycidyl ether dimethacrylate } \\
\text { Triethylene glycol dimethacrylate } \\
\text { Dichlorodimethylsilane reaction product with silica } \\
\text { Benzoyl peroxide }\end{array}$ & $\begin{array}{c}40-50 \\
40-50 \\
1-10 \\
1-10 \\
40-50 \\
40-50 \\
<2 \\
\\
75-85 \\
10-20 \\
1-10 \\
<2 \\
\\
70-80 \\
15-25 \\
1-10 \\
<2 \\
<0.3 \\
\end{array}$ \\
\hline TSEP & $\begin{array}{l}\text { Methacrylate ester derivative } \\
\text { Water }\end{array}$ & $\begin{array}{l}75-85 \\
15-25\end{array}$ \\
\hline TMIP & $\begin{array}{l}\text { Ethyl Alcohol } \\
\text { Bisphenol A Diglycidyl ether dimethacrylate } \\
\text { 2-Hydroxyethyl Methacrylate } \\
\text { 2-Hydroxy-1,3-Dimethacryloxypropane } \\
\text { Copolymer itaconic and acrylic acid } \\
\text { Diurethane Dimethacrylate } \\
\text { Water }\end{array}$ & $\begin{array}{c}30-40 \\
10-30 \\
10-30 \\
7-13 \\
7-13 \\
3-7 \\
3-7\end{array}$ \\
\hline Smart-Bond & $\begin{array}{l}\text { Ethyl cyanocrylate } \\
\text { Poly methylmethacrylate } \\
\text { Silica. Amorphous trated } \\
\text { Hydroquinone }\end{array}$ & $\begin{array}{c}85-90 \\
5-10 \\
5-10 \\
0.1-0.5\end{array}$ \\
\hline
\end{tabular}


facturers' instructions. Bonding procedures were carried out by the same operator using a standard technique.

LC materials were exposed to a light source (Optilux 400, Demetron Research Corp, Danbury, Conn, USA) at the bracket's gingival and incisal margins for 20 seconds and then exposed to a further 20 seconds transillumination with visible light through the palatal side of the tooth. The light was tested for light output $(>600$ $\mathrm{mW} / \mathrm{cm} 2$ ) before each use with a Demetron radiometer (model 100, Demetron Research Corp). After an initial polymerization of 15 minutes at room temperature and high levels of environmental humidity, specimens were stored in distilled water for 24 hours at $370 \mathrm{C}$ to allow the adhesives to harden.

Afterwards, samples were thermocycled 500 times (from $50 \mathrm{C}$ to $550 \mathrm{C}$, with a dwell time of 30 seconds). Teeth were mounted on acrylic block frames and brackets were debonded using a Universal testing machine (Instron Corp., Canton, MA, USA) at a crosshead speed of $1 \mathrm{~mm} / \mathrm{min}$ until fracture ocurred. Shear bond values (SBS) were recorded in Nw. and mean and standard deviations were calculated.

The debonded surfaces were examined with a stereomicroscope (Olympus Optical Co., Hamburg,Germany) to identify the mode of failure. Failure modes were categorized as follows: bond failure resin-enamel interface, bond failure bracket-resin interface and mixed failure. Numerical data were subjected to variance analysis (ANOVA) and the Student-Newman-Keuls multiple comparison test. Analysis of failure sites was carried out by means of chi-squared analysis. Statistical significance was set at 0.05 .

\section{Results}

SBS data are listed in (Table 2). Under dry conditions, SBS for Smart-Bond was significantly lower than values achieved by the other groups $(\mathrm{p}<0.05)$. No significant differences were found between SBS values for adhesives bonded in a wet field $(\mathrm{p}>0.05)$. For each adhesive, no significant differences in SBS values were detected between dry and wet enamel $(\mathrm{p}>0.05)$, with the exception of SmartBond, whose SBS in wet conditions was significantly higher than in a dry environment $(\mathrm{p}<0.05)$.

Bond failure modes are shown in (Table 3). No significant differences in bond failure site location were noted between the adhesives in dry conditions $(\mathrm{p}>0.05)$. For TSEP/Transbond XT, Fuji Ortho LC, Concise, and Acid/ Transbond XT most of the failures $(87 \%, 75 \%, 85 \%$, and $78 \%$ respectively) were mixed, while for Smart-Bond $62 \%$ of the failures were at the adhesive bracket interface. When the adhesives were bonded to wet enamel, significant differences were found between failure sites for the different groups $(\mathrm{p}<0.05)$. For TSEP/Transbond XT $50 \%$ of the failures were mixed and $50 \%$ were at the enamel-adhesive interface, while for Fuji Ortho LC, TMIP/Concise and Acid/Transbond the most of the failures $(77 \%, 80 \%$, and $60 \%)$ were mixed. SmartBond showed $55 \%$ of failures at the adhesive-bracket interface and $45 \%$ were mixed failures. No significant differences were detected in failure sites for each adhesive between bonding on dry or wet enamel ( $p>0.05)$.

Table 2. Mean shear bond strength (Nw) and standard deviation (SD) for each group $(\mathrm{n}=10)$.

\begin{tabular}{|c|c|c|}
\hline \multirow{2}{*}{ Group } & Dry & Wet \\
\cline { 2 - 3 } & Mean \pm S.D. & Mean \pm S.D. \\
\hline Acid/Transbond XT & $21.83 \pm 7.57 \mathrm{Aa}$ & $20.25 \pm 7.09 \mathrm{Aa}$ \\
\hline TSEP/Transbond XT & $16.83 \pm 4.93 \mathrm{Aa}$ & $20.37 \pm 5.88 \mathrm{Aa}$ \\
\hline Concise* & $20.58 \pm 5.27 \mathrm{Aa}$ & $18.85 \pm 4.77 \mathrm{Aa}$ \\
\hline Fuji Ortho LC & $22.75 \pm 6.64 \mathrm{Aa}$ & $17.06 \pm 5.29 \mathrm{Aa}$ \\
\hline Smart-Bond & $7.32 \pm 3.93 \mathrm{Ba}$ & $14.47 \pm 5.84 \mathrm{Ab}$ \\
\hline
\end{tabular}

* On wet surfaces after etching, the enamel was primed with Transbond MIP instead of Concise primer.

Data were analysed by ANOVA and Student-Newman-Keuls multiple comparison tests. Within the same column, identical upper case letters indicate no differences. For each row, matching lower case letters indicate no differences. $\mathrm{P}<0.05$. 
Table 3. Site of failure. Number of specimens and percentage of specimens in each material group $(\mathrm{n}=10)$.

\begin{tabular}{|c|c|c|c|c|c|c|}
\hline \multirow{2}{*}{ Group } & \multicolumn{3}{|c|}{ Dry } & \multicolumn{3}{|c|}{ Wet } \\
\hline & Resin-Enamel & Bracket-Resin & Mixed & Resin-Enamel & Bracket-Resin & Mixed \\
\hline Acid/Transbond XT & $1(11 \%)$ & $1(11 \%)$ & $6(78 \%)$ & $1(10 \%)$ & $3(30 \%)$ & $6(60 \%)$ \\
\hline $\begin{array}{c}\text { TSEP/Transbond } \\
\text { XT }\end{array}$ & $1(23 \%)$ & $0(0 \%)$ & $7(87 \%)$ & $5(50 \%)$ & $0(0 \%)$ & $5(50 \%)$ \\
\hline Concise * & $1(15 \%)$ & $0(0 \%)$ & $6(85 \%)$ & $2(20 \%)$ & $0(0 \%)$ & $8(80 \%)$ \\
\hline Fuji Ortho LC & $1(12.5 \%)$ & $1(12.5 \%)$ & $6(75 \%)$ & $1(11.15 \%)$ & $1(11.15 \%)$ & $7(77 \%)$ \\
\hline Smart-Bond & $0(0 \%)$ & $5(62 \%)$ & $3(38 \%)$ & $0(0 \%)$ & $5(55 \%)$ & $4(45 \%)$ \\
\hline
\end{tabular}

* On the wet surfaces after etching, the enamel was primed with Transbond MIP instead of Concise primer.

The chi-squared test showed significant differences between the site of failure of the different groups under wet conditions. No significant differences were detected between the adhesives under dry conditions, nor for each adhesive when bonding on dry or wet enamel. $\mathrm{P}<0.05$

\section{Discussion}

In order to achieve successful bonding to dentin, manufacturers have improved the hydrophylic properties of adhesives. The introduction of these materials, which are less sensitive to wet conditions, should be useful for bracket bonding when moisture is present.

The inefficiency of some resin adhesive systems in the presence of moisture has long been known. In our study, the SBS provided by Transbond XT in dry conditions was higher than the strength achieved in wet condition, however, no significant differences were found with this adhesive in both conditions .

Fuji Ortho LC is a light-cured RMGIC for specific use in orthodontics. It have been shown that the SBS of Fuji Ortho LC is similar to that achieved by chemically and light-cured composite resins (9). The current findings indicate that Fuji Ortho LC used on etched enamel in the presence of a thin film of water is capable of providing a shear bond strength that is able to withstand routine orthodontic forces. Even when contaminated with water before bonding, the light-cured RMGIC obtains a SBS comparable to the traditional chemically and light-cured composite resin systems. These results are in accordance with those obtained by Bishara et al. (10). Other authors found that the bond strength of Fuji Ortho on etched enamel was significantly higher when the enamel was dry than when contaminated with water (11), However we can not compare our results with those obtained by these authors because they did not thermocycle the samples.

The effective bond produced by the resin-modified glass ionomer in the presence of water could have three plausible explanations: 1) The cementing agent may be able to displace a sufficient amount of water so that the chemical bonding between the resin-modified glass ionomer and the calcium in the tooth is not impeded (12). 2) The water present is simply incorporated into the cement because water is the carrier for the acidic component in this reaction (12). 3) Another explanation might be the presence of HEMA as a major constituent of the resin component in Fuji Ortho LC; this watersoluble hydrophilic monomer is an essential ingredient to inducing wetting and penetration (13).

SmartBond is a single-phase, particle-filled adhesive, based on cyanocrylate chemistry, which sets in the presence of water (2). One of the significant advantages of cyanoacrylate adhesives is their ability to polymerize as a thin film at room temperature without a catalyst when pressure is applied in a moist environment (14). Our results showed that this product requires, rather than tolerates, the presence of water for proper polymerization (moisture-active adhesive). The SBS of Smart-Bond in wet conditions was therefore significantly higher than in a dry environment. Under dry conditions, the shear bond strength of the cyanocrilate-based adhesive was significantly lower than that obtained with the other bonding materials. However, when the enamel was soaked with water no significant differences were found between SmartBond and the other systems evaluated. The setting reaction of this product involves two steps. First, isocyanate groups react with water, forming an unstable carbamic acid component, which rapidly decomposes to carbon dioxide and the corresponding amine. Secondly, the amine reacts with residual isocyanate groups, crosslinking the adhesive through substituted urea groups (2). Our results concur with those obtained by Bishara 
et al. (15) who also found no significant differences in Smart-Bond's SBS when compared with Transbond-XT. However others have reported significantly lower SBS values for Smartbond than for resin composites (14). The effect of moisture on the SBS of hydrophilic orthodontic primers appears to be controversial. These primers are adaptations of dentin-bonding agents, which have hydrophilic components such as HEMA, allowing a lower contact angle and an extension of the molecule that bonds to the resin composite (1). Our study suggests that TMIP in moist conditions either penetrated and displaced the moisture or dried the etched enamel and yet still produced a SBS similar to that obtained with Concise and its conventional primer in dry conditions. The success of TMIP in wet conditions could be due to either the primer's ethanol solvent, the addition of HEMA to the primer or to both.

Our results suggested that for teeth bonded with TSEP there was no significant difference in SBS on wet or dry enamel and this is in accordance with results quoted in literature $(16,17)$. Other authors have proved that the SBS of self-etching primers was significantly reduced in the presence of moisture $(18,19)$. It has been shown that the chemical reaction of self-etching primers on enamel takes place concomitantly with the chemisorption of the primers into the enamel surfaces. Not only can Phosphoric acid esters decalcify hydroxyapatite, but also they can adhere chemically to the hydroxyapatite. In this way, a self-etching priming agent based on phosphoric acid esters (PAEs) offers a promising approach to adhesive dentistry, since it possesses the ability to etch and adhere chemically to hydroxyapatite in addition to its capacity for micro-mechanic hybridation (20). The chemical adhesion of self-etching primers could explain their tolerance to moisture. Another possible explanation could be the presence of water in their composition. Water is necessary to activate the self-etching primer and obtain an adequate $\mathrm{pH}$.

Regarding the site locations of bond failure, no significant differences were detected for each adhesive between wet and dry conditions. Most of the failures were mixed, except for SmartBond, which had more than half of the failures at the adhesive-bracket interface. This is probably due to incomplete polymerisation of the resin below the bracket base.

One of the problems in the investigation of bonding systems that tolerate moisture is that the effectiveness of the system may vary with the degree of moisture contamination. This might explain the variation of results between different studies.

\section{Conclusions}

No significant differences were detected in SBS for each system between wet and dry enamel with the exception of SmartBond. The SBS of SmartBond was signifi- cantly lower under dry conditions than wet. According to the manufacturer, this system requires the presence of water for proper polymerization. In this way, when bonding under wet conditions, the bonding capacity of the other adhesives tested was similar to that achieved under dry conditions.

\section{References}

1. Rajagopal R, Padmanabhan S, Gnanamani J. A comparison of shear bond strength and debonding characteristics of conventional, moisture-insensitive, and self-etching primers in vitro. Angle Orthod. 2004;74:264-8.

2. Eliades T, Katsavrias E, Eliades G. Moisture-insensitive adhesives: reactivity with water and bond strength to wet and saliva-contaminated enamel. Eur J Orthod. 2002;24:35-42.

3. Cacciafesta V, Sfondrini MF, Scribante A, De Angelis M, Klersy C. Effect of blood contamination on shear bond strength of brackets bonded with a self-etching primer combined with a resin-modified glass ionomer. Am J Orthod Dentofacial Orthop. 2004;126:703-8.

4. Cohen WJ, Wiltshire WA, Dawes C, Lavelle CL. Long-term in vitro fluoride release and rerelease from orthodontic bonding materials containing fluoride. Am J Orthod Dentofacial Orthop. 2003;124:571-6.

5. Vicente A, Bravo LA, Romero M, Ortíz AJ, Canteras M. Shear bond strength of orthodontic brackets bonded with self-etching primers. Am J Dent. 2005;18:256-60.

6. Yamada R, Hayakawa T, Kasai K. Effect of using self-etching primer for bonding orthodontic brackets. Angle Orthod. 2002;72:558-64.

7. Buyukyilmaz T, Usumez S, Karaman AI. Effect of self-etching primers on bond strength--are they reliable? Angle Orthod. 2003;73:64-70.

8. Miyazaki M, Hirohata N, Takagaki K, Onose H, Moore BK. Influence of self-etching primer drying time on enamel bond strength of resin composites. J Dent. 1999;27:203-7.

9. Chitnis D, Dunn WJ, Gonzales DA. Comparison of in-vitro bond strengths between resin-modified glass ionomer, polyacid-modified composite resin, and giomer adhesive systems. Am J Orthod Dentofacial Orthop. 2006;129:330.e11-6.

10. Bishara SE, Olsen ME, Damon P, Jakobsen JR. Evaluation of a new light-cured orthodontic bonding adhesive. Am J Orthod Dentofacial Orthop. 1998;114:80-7.

11. Itoh T, Matsuo N, Fukushima T, Inoue Y, Oniki Y, Matsumoto $\mathrm{M}$, et al. Effect of contamination and etching on enamel bond strength of new light-cured glass ionomer cements. Angle Orthod. 1999;69:450-6.

12. Reddy L, Marker VA, Ellis E 3rd. Bond strength for orthodontic brackets contaminated by blood: composite versus resin-modified glass ionomer cements. J Oral Maxillofac Surg. 2003;61:206-13.

13. Cacciafesta V, Jost-Brinkmann PG, Süssenberger U, Miethke RR. Effects of saliva and water contamination on the enamel shear bond strength of a light-cured glass ionomer cement. Am J Orthod Dentofacial Orthop. 1998;113:402-7.

14. Al-Munajed MK, Gordon PH, McCabe JF. The use of a cyanoacrylate adhesive for bonding orthodontic brackets: an ex-vivo study. $\mathrm{J}$ Orthod. 2000;27:255-60.

15. Bishara SE, VonWald L, Laffoon JF, Warren JJ. Effect of using a new cyanoacrylate adhesive on the shear bond strength of orthodontic brackets. Angle Orthod. 2001;71:466-9.

16. Sirirungrojying S, Saito K, Hayakawa T, Kasai K. Efficacy of using self-etching primer with a 4-META/MMA-TBB resin cement in bonding orthodontic brackets to human enamel and effect of saliva contamination on shear bond strength. Angle Orthod. 2004;74:251-8.

17. Bishara SE, Oonsombat C, Ajlouni R, Denehy G. The effect of saliva contamination on shear bond strength of orthodontic brackets when using a self-etch primer. Angle Orthod. 2002;72:554-7.

18. Campoy MD, Vicente A, Bravo LA. Effect of saliva contamiina- 
tion on the shear bond strength of orthodontic brackets bonded with a self-etching primer. Angle Orthod. 2005;75:865-9.

19. Cacciafesta V, Sfondrini MF, De Angelis M, Scribante A, Klersy

C. Effect of water and saliva contamination on shear bond strength of brackets bonded with conventional, hydrophilic, and self-etching primers. Am J Orthod Dentofacial Orthop. 2003;123:633-40.

20. Fu B, Sun X, Qian W, Shen Y, Chen R, Hannig M. Evidence of chemical bonding to hydroxyapatite by phosphoric acid esters. Biomaterials. 2005;26:5104-10. 